\title{
CENTRALIDADE E ÁREA DE INFLUÊNCIA DE SÃO PAULO DO POTENGI/RN NA REDE URBANA REGIONAL
}

\author{
Edseisy Silva Barbalho Tavares ${ }^{1}$ \\ Dina Gomes ${ }^{2}$ \\ Escarlaty Porfírio ${ }^{3}$
}

\begin{abstract}
Resumo
Centros urbanos de diferentes níveis da hierarquia da rede urbana do Rio Grande do Norte têm apresentado modificações quanto ao seus papeis, funções e centralidade. Neste sentido, o objetivo deste trabalho é analisar a centralidade de São Paulo do Potengi/RN, no período atual, na rede de influência regional. Para tanto, foram identificados os principais fluxos desse centro urbano nos estudos do IBGE, realizado em 2008 e analisados os usos do território que mais movimentam fluxos nesse centro urbano entre 2018 e 2019. A pesquisa contemplou um estudo teórico-conceitual e empírico, abordando discussões sobre a urbanização do território, rede urbana e usos do território e apresentou como variáveis de análise os sistemas técnicos de telecomunicações e transportes bem como redes de comércio e serviços. Constatamos que novas redes de interações territoriais estão sendo estabelecidas com fluxos que expandiram sua área de influência.
\end{abstract}

Palavras-chave: São Paulo do Potengi. Rede Urbana. Centralidade.

\section{CENTRALITY AND INFLUENCE AREA OF SÃO PAULO DO POTENGI/RN IN THE REGIONAL URBAN NETWORK}

\begin{abstract}
Urban Centers at different levels of the hierarchy of the Rio Grande do Norte urban network show changes in their roles, functions and centrality. In this sense, the aim of this paper is analyze the centrality of São Paulo do Potengi/RN in the current period in the regional influence network. Therefore, the main flows of this urban center were identified in the IBGE studies, conducted in 2008 and analyzed the territory uses that most move flows in this urban center between 2018 and 2019. The research included a theoretical-conceptual and empirical study, approaching discussions about the territory urbanization, urban network, territory uses and has presented as variables analysis telecommunications and transport as well as networks of commerce and services technical systems. We find that new networks of territorial interactions are being established with flows that have expanded their areas of influence.

\footnotetext{
${ }^{1}$ Professora do Instituto Federal de Educação Ciência e Tecnologia do Rio Grande do Norte (IFRN). Doutora em Geografia pelo PPGE/UFRN. Email: edseisy.tavares@ifrn.edu.br

${ }^{2}$ Cursando Técnico de Nível Médio em Meio Ambiente, na Forma Integrado no Instituto Federal de Ciência e Tecnologia do Rio Grande do Norte / Campus São Paulo do Potengi.

${ }^{3}$ Cursando Técnico de Nível Médio em Meio Ambiente, na Forma Integrado no Instituto Federal de Ciência e Tecnologia do Rio Grande do Norte / Campus São Paulo do Potengi.
} 
Key-words: São Paulo do Potengi. Urban Network. Centrality.

\section{CENTRALIDAD Y ÁREA DE INFLUENCIA EN SÃO PAULO DO POTENGI/RN EM LA RED URBANA REGIONAL}

\section{Resumen}

Los centros urbanos en diferentes niveles de la jerarquía de la red urbana en Rio Grande do Norte han mostrado cambios en sus papeles, funciones y centralidad. En este sentido, el objetivo de este trabajo es analizar la centralidad de São Paulo do Potengi/RN em el período actual em la red regional de influencia. Para esto, lós principales flujos de este centro urbano se identificaron em los estúdios del IBGE, realizados en 2008 y se analizaron los usos del territorio que mueven La mayor cantidad de flujos en este centro urbano entre 2018 y 2019. La investigación contemplo um estudio teórico-conceptual y empírico, abordando discusiones sobre la urbanización del territorio, la red urbana y los usos del territorio y tuvo como variables de análisis los sistemas técnicos de telecomunicaciones y transporte y las redes de comercio y servicios. Encontramos que se están estableciendo nuevas redes de interacciones territoriales com flujos que han expandido su área de influencia.

Palabras-clave: São Paulo do Potengi. Red Urbana. Centralidad.

\section{INTRODUÇÃO}

A rede urbana do Rio Grande do Norte, da década de 1960 até o período atual, passou por alterações quanto ao papel e níveis de centralidade apresentados por algumas de suas cidades, conforme, é possível constatar nas Regiões de Influência das Cidades (REGICS) de 1966, 1978, 1993 e 2007. A REGIC consiste em um estudo realizado pelo IBGE, que representa a mais completa referência de estudo sobre a rede urbana na escala nacional, contemplando um embasamento teórico e variáveis pertinentes a cada período, de maneira a identificar, em linhas gerais, as principais centralidades da rede urbana do Brasil e de cada estado. Contudo, é preciso atentar que, apresentando diferentes concepções teóricas, metodologias e variáveis, essas questões devem ser consideradas nas análises, dado que a posição das cidades na hierarquia urbana pode ser alterada. Esse contexto, implica, inclusive, em dificuldades de comparação entre a estrutura apresentada pela rede urbana nos diferentes estudos.

Os centros urbanos do estado que, no atual período, são classificados com centros de gestão do território, seguindo a tendência nacional, são majoritariamente centros que já exerciam alguma centralidade desde a década de 1960 (IBGE/REGIC, 2008). Entretanto, não foram apenas os centros que já exerciam centralidade que se tornaram centros de gestão do 
território. Cidades que nem exerciam centralidade em 1966, ascenderam posições na hierarquia urbana no estudo de 2007, tal como ocorreu com São Paulo do Potengi, que era um Centro local e se tornou um Centro de zona $\mathrm{B}^{4}$.

São Paulo do Potengi nas três primeiras REGICs foi classificado como um centro urbano local cuja centralidade não ultrapassava os limites territoriais. Em 2007, ascendeu na hierarquia a Centro de zona $\mathrm{B}$, que assim como os centros de zona $\mathrm{A}$, não são considerados centros de gestão relevante, mas exercem centralidade e convergência de fluxos de outros municípios. A sua área de influência passou a movimentar fluxos provenientes dos municípios de Barcelona, Lagoa de Velhos, Santa Maria, Riachuelo, Ruy Barbosa, São Pedro e Senador Elói de Souza.

Mudanças podem ser observadas quanto aos papeis e níveis de centralidade de algumas cidades do estado, nesses estudos, sobretudo, nos últimos dez anos quando a difusão de novos usos do território vem permitindo lógicas mais dinamizadoras que desarticularam as combinações pretéritas e criaram novas configurações espaciais para a rede urbana, como esclarece Bessa (2010).

São Paulo do Potengi, desde o último estudo realizado pelo IBGE, apresenta uma expansão e nova dinâmica, tanto em relação aos sistemas de telecomunicações e transportes, quanto ao que se refere às possibilidades criadas para a espacialização do comércio varejista e de determinados serviços, o que nos faz questionar qual o papel, nível de centralidade e zona de influência de São Paulo do Potengi na rede urbana estadual. De tal modo, o objetivo deste trabalho é analisar a centralidade de São Paulo do Potengi/RN, no período atual, na rede de influência regional. Portanto, o estudo aponta para as novas interações territoriais que podem ocorrer em diversos níveis da hierarquia urbana a partir dos fluxos gerados pela instalação de novas infraestruturas e atividades comerciais e de serviços urbanos modernos.

Assim, a pesquisa é encaminhada no sentido de entendermos os diversos usos do território de São Paulo do Potengi, a partir dos últimos dez anos e, como estes promoveram uma dinâmica territorial que, relacionada a diversas escalas e com outros fenômenos, desenvolve no município e especialmente no seu centro urbano um processo de centralidade regional no contexto da rede urbana.

\footnotetext{
${ }^{4}$ Apesar de não ser possível comparações diretas entre os estudos, a análise destes nos permite compreender que na base da hierarquia urbana em todos os casos, estão os centros urbanos cuja centralidade não extrapola os seus limites territoriais.
} 
Nessa perspectiva, nosso caminho de pesquisa inicia com investigações sobre o processo de urbanização do território, buscando entender como se dispõem o arranjo espacial e a rede de relações que são estabelecidas entre São Paulo do Potengi e sua área de influência, assim como as variáveis que podem ser consideradas para a compreensão dessa rede. As variáveis, a partir das quais vem sendo realizada a nossa análise, estão vinculadas aos sistemas técnicos de telecomunicações e transportes (infraestrutura e fluxos); aos serviços bancários, educacionais, judiciários e de saúde; às redes de comércio varejista principalmente de caráter associativistas de abrangência territorial e capital local e aos fluxos movimentados pela feira livre. A seleção das variáveis ocorreu considerando as redes que são estabelecidas para a realização dessas atividades, possibilitando uma análise da rede urbana regional, isto porque a forma como se superpõem e a disposição dos objetos e os fluxos gerados revelam como o centro urbano de São Paulo do Potengi apresenta novas interações territoriais na sua região.

A centralidade e as interações territoriais foram investigadas a partir dos dados da REGIC e por intermédio da obtenção de dados e produção de informações. A obtenção de dados, a partir de fontes, ocorreu por intermédio de pesquisa bibliográfica a respeito do tema em estudo e pesquisa documental em órgãos e/ou instituições públicas e privadas responsáveis por dados históricos e estatísticos concernentes aos fluxos de pessoas e a instalação das atividades comerciais e serviços que densificaram diferenciadamente esse centro urbano do estado.

Foram solicitadas informações nas empresas comerciais, nas agências e correspondentes bancários, no cartório eleitoral e Fórum Municipal, nas escolas públicas e privadas, Secretaria de Educação Municipal, Instituto Federal e Universidade privada e na Secretaria de Saúde Pública e clínicas privadas. Para o levantamento de informações, os procedimentos realizados foram entrevistas, com perguntas abertas e fechadas com a sociedade, as instituições, as firmas, ou seja, os diversos agentes sociais envolvidos no estudo em tela.

Assim sendo, entrevistamos os agentes diretamente vinculados aos setores da normatização, produção, circulação, comercialização e prestação de serviços públicos e privados, além dos relacionados aos fluxos de transporte de passageiros, tanto dos transportes regulares como ônibus, como também dos carros de lotação e vans. Portanto, para compreender a centralidade do município de São Paulo do Potengi analisamos os fluxos que ocorrem entre esse centro urbano e os demais municípios. 


\section{A CENTRALIDADE E A ÁREA DE INFLUÊNCIA dE SÃO PAULO DO POTENGI A PARTIR DOS NOVOS FLUXOS}

A rede urbana potiguar passa a se reestruturar a partir dos novos usos do território ocorridos entre as décadas de 1960 e 1970 quando surgem os primeiros indícios da constituição de um meio técnico-científico-informacional, com a inserção de técnica, ciência e informação na implementação e expansão, por exemplo dos sistemas de transporte, energia e telefonia. Contudo, esse processo só se intensifica a partir dos anos 1990, com a difusão mais acentuada desse meio no território do estado. No entanto, é preciso pontuar que a disseminação do meio técnico-científico-informacional não ocorre de forma homogênea, nem como um todo, pois "em nenhum caso a difusão dos objetos técnicos se dá uniformemente ou de modo homogêneo. Essa heterogeneidade vem da maneira como eles se inserem desigualmente na história e no território, no tempo e no espaço" (SANTOS, 2012, p. 39). Em São Paulo do Potengi, apesar de também receber algumas das novas técnicas desse período, uma maior densidade desses objetos e de outras atividades comerciais e serviços, que inclusive as utilizam, se instalam na última década.

Como ocorre em outras regiões do país, é possível constatar mudanças nos papeis e na dinâmica da rede urbana potiguar, pois cidades de distintos níveis da hierarquia urbana, têm incorporadas ao território densidades diferentes de técnica, ciência e informação, o que vem modificando a importância que elas têm na rede urbana. Situação que também se manifesta em São Paulo do Potengi e que, portanto, modifica a sua centralidade na região e as relações com a zona de influência que passa a contemplar.

De acordo com Santos (2008, p. 68), “a rede urbana é um conjunto de aglomerações produzindo bens e serviços junto com uma rede de infraestrutura de suporte e com os fluxos que, através desses instrumentos de intercâmbio, circulam entre as aglomerações”. Assim, a rede urbana se estabelece por uma superposição de redes que coabitam, de modo que em todas as escalas e também no âmbito estadual, os usos do território ao longo dos períodos, organizam diversas redes de relações entre as cidades. Considerando que no lugar acontece algumas das possibilidades do mundo, São Paulo do Potengi apresenta na rede urbana estadual uma combinação particular, que se relaciona com as demais redes e cidades, também por intermédio de relações específicas. 


\section{INFRAESTRUTURA E REDES DE TRANSPORTE, ENERGIA E TELECOMUNICAÇÕES}

Os fluxos dos transportes nos revelam os deslocamentos e, consequentemente, sua presença e intensidade permitem compreender para onde os fluxos estão convergindo. Para Spósito (2001, p. 238), “os fluxos permitem a apreensão da centralidade, porque é através dos nódulos de articulação intra e interurbana que ela se revela”. Costa (1977, p. 76) também esclarece a importância apresentada pelos transportes "para a compreensão da organização da rede urbana, uma vez que geralmente convergem para as cidades maiores, constituindo-se nas "vias por onde os fluxos se fazem"'.

Nessa perspectiva, como forma de compreender a centralidade de São Paulo do Potengi, analisamos os fluxos que ocorrem entre essa cidade e demais municípios por intermédio, por exemplo, dos transportes coletivos, ou seja, os transportes regulares como ônibus, assim como os carros de lotação e vans ${ }^{5}$. Apesar da REGIC considerar apenas os transportes regulares, constatamos na pesquisa in loco nos pontos de paradas dos transportes intermunicipais a presença dos referidos transportes informais, por isso, também os contemplamos no estudo. Os deslocamentos realizados em direção a São Paulo do Potengi por intermédio de transporte coletivo, registrados na REGIC de 2008, permanecem os mesmos em 2019, que são fluxos de Barcelona, Lagoa de Velhos, Ruy Barbosa, São Pedro, São Tomé e Senador Elói de Souza.

Contudo, foram identificados pau de arara, ônibus e carros de lotação também de Riachuelo e Santa Maria. Na REGIC de 2008 esses centros só apresentavam destinos de transportes coletivos entre eles e com Natal. E de Riachuelo havia deslocamento por transportes coletivos para Caiçara do Rio do Vento. Apesar de não termos os fluxos realizados por transporte coletivo, em 2008, para Riachuelo e Santa Maria, esses municípios já aparecem na área de influência de São Paulo do Potengi. E o fato de hoje existirem essas opções de transporte, mesmo que não sejam regulamentados (como a maioria dos transportes de passageiros que ocorre hoje no estado), ratifica a influência de São Paulo do Potengi também nesses municípios.

\footnotetext{
${ }^{5}$ Para um número significativo de municípios do interior do estado, o transporte coletivo realizado pelos ônibus não atendia as demandas da população, principalmente no que se refere a disponibilidade diversa de horários. Nesse sentido, surgem os transportes que conseguem realizar um maior número de viagens diárias com reduzido número de passageiros em cada uma delas.
} 
No serviço de telefonia, constatamos que, diferentemente do que ocorre com o serviço de telefonia fixa, o sistema de telefonia móvel cresce vertiginosamente no Rio Grande do Norte. De acordo com dados da Pesquisa Nacional de Amostra e Domicílios (PNAD), em 2005, 31,6\% da população do estado utilizava o telefone móvel, percentual que cresce, em 2015, para 75,6\% segundo a última pesquisa divulgada pela PNAD (IBGE 2005/2015).

Se nas décadas anteriores $(1990,2000)$ a telefonia móvel era restrita tanto em função do valor do aparelho, quanto do valor do serviço, pois se tratava de um serviço no qual as tarifas eram muito altas de modo que impossibilitavam o seu uso efetivo, hoje, o sistema de telefonia móvel é mais acessível, por existirem aparelhos de preços variados no mercado e várias opções de crediário. Além disso, há ainda um elevado número de pacotes promocionais aos usuários a partir do sistema pré-pago e pós-pago que permitem a expansão do sistema.

Com a difusão dessa rede de telecomunicações que possibilitou uma maior conexão entre os lugares, a telefonia móvel torna-se um dos principais meios de comunicação utilizados pela população para a realização de diversas atividades. Esse sistema movimenta fluxos de informações, sendo, para muitos, a única opção de telefonia utilizada, inclusive para o trabalho que desenvolvem. É por intermédio desse objeto técnico que uma parcela da população consegue realizar os contatos necessários à realização de suas atividades profissionais e pessoais.

Atuam no estado cinco operadoras de telefonia móvel: Vivo, Claro, Tim, Oi e Nextel, esta última presente apenas em Natal, sendo que a maioria dos usuários utilizam o sistema pré-pago, o que não difere do ocorrido nas demais partes do país. A força da telefonia móvel no período atual é revelada pela presença do serviço em todo o território estadual, pois todos os municípios têm o atendimento por parte de, pelo menos, uma operadora. $\mathrm{Na}$ área de influência de São Paulo do Potengi, apenas Santa Maria e São Paulo do Potengi contam com a cobertura de mais de uma operadora, duas e três, respectivamente. Portanto, seguindo a tendência dos demais centros urbanos do estado que exercem centralidade regional, São Paulo do Potengi tem a cobertura da maioria das empresas (TELECO, 2019).

Assim, entendemos que, entre outros fatores, convergem para a maior ou menor densidade de telefonia móvel nos lugares o fato de se ter "atividades econômicas mais ou menos modernas, níveis de renda, densidade da população urbana e rural, padrões de consumo, demandas não atendidas de telefonia fixa” (SANTOS; SILVEIRA, 2003, p. 84). 
Além da telefonia, a internet é outro elemento essencial do sistema de telecomunicação. Esse sistema exerce grande influência sobre o uso do território estadual, tanto do ponto de vista material, quanto das ações, uma vez que reorganiza as relações sociais e as interações territoriais ocorridas no período atual entre os subespaços estaduais e as diversas escalas espaciais. Daí Castells (1999, p. 89) afirmar que "a lógica de funcionamento de redes, cujo símbolo é a Internet, tornou-se aplicável a todos os tipos de atividade, a todos os contextos e a todos os locais que pudessem ser conectados eletronicamente". A cobertura de serviço móvel de internet 4G, segundo a TELECO (2019) só se encontra disponível em Santa Maria, Riachuelo e São Paulo do Potengi.

A Companhia Energética do Rio Grande do Norte (COSERN) responsável pelo serviço de distribuição de energia elétrica no estado, disponibiliza aos seus consumidores diversas opções de canais de atendimento e utilização dos serviços, que vão desde o atendimento presencial, ao uso dos sistemas de telecomunicações, como telefone, site e $e$ mail. Nessa esteira, temos mudanças na logística das interações territoriais, devido ao acesso a uma série de serviços como, por exemplo, emissão de segunda via de pagamento, consulta de solicitação de serviços, novas ligações e reclamações de consumo poderem ser solucionados de qualquer localidade do estado, seja pelo telefone ou internet (agência virtual) sem que haja a necessidade de deslocamentos a uma agência física em algumas das principais centralidades do território potiguar, ou seja, nas cidades que são consideradas centros de gestão do território pela REGIC (IBGE/REGIC, 2008). Mas, caso o cliente precise ou opte pelo atendimento presencial, a disponibilidade do posto de atendimento da COSERN na região do Potengi, será em São Paulo do Potengi, contemplando uma área de abrangência que extrapola a influência identificada pela REGIC (IBGE/REGIC, 2008), considerando que atende além dos municípios já anunciados, Bento Fernandes, Boa Saúde, Bom Jesus, Caiçara do Rio do Vento, Jardim de Angicos, Ielmo Marinho, São José do Campestre, São Tomé, Serra Caiada, Sítio Novo e Tangará.

\section{SERVIÇOS EDUCACIONAIS, DE SAÚDE, BANCÁRIOS E JUDICIÁRIOS}

São Paulo do Potengi era um Centro local e foi considerado segundo a última REGIC (IBGE/REGIC, 2008), um Centro de zona B, mas a dinâmica desse centro urbano também vem modificando na última década, em decorrência da implementação e expansão de novos equipamentos de comércio e serviços urbanos no território estadual. A depender de sua localização, essas atividades reforçam algumas centralidades que já apresentam importância 
na rede urbana do Rio Grande do Norte, mas também criam fluxos em direção a centros que estão na base da hierarquia urbana, estabelecendo nestes uma dinâmica que vai além dos seus limites territoriais. De acordo com Spósito (2010, p. 53),

\begin{abstract}
Não se trata da substituição de redes urbanas hierárquicas por outros tipos de redes, mas da combinação complexa e contraditória de fluxos que se estabelecem tanto no sentido hierárquico, como no sentido horizontal ou transversal, uma vez que uma mesma cidade é o espaço da ação e decisão de atores econômicos que se relacionam em diferentes escalas. Trata-se da sobreposição de redes organizadas por vetores de diferentes naturezas e intensidades, gerando o que já se denominou de "rede de redes".
\end{abstract}

Algumas atividades que mais movimentam fluxos no estado nos últimos anos e que, portanto, nos remete às funções e a centralidade que podem ser exercidas por um centro urbano, se expandiram, foram reforçadas ou se instalaram em São Paulo do Potengi, criando uma nova dinâmica na cidade. Entre essas atividades se destacam os serviços de educação, saúde, financeiros e os serviços judiciários com o Fórum Municipal e o Cartório Eleitoral, além da presença de uma Delegacia Regional. Esses serviços também foram analisados na REGIC de 2008. No entanto, verificamos conforme mencionado, a expansão e aumento da centralidade desse centro urbano, com a propagação da sua área de influência para outros municípios.

Os fluxos movimentados pelos serviços de educação revelam essa mudança. De acordo com o último estudo realizado pelo IBGE (IBGE/REGIC, 2008), os deslocamentos em direção a São Paulo do Potengi para cursos de nível superior eram dos municípios de Barcelona, Lagoa de Velhos, Santa Maria, Riachuelo, Ruy Barbosa, São Pedro, São Tomé e Senador Elói de Souza. Todavia, considerando os municípios de residência dos alunos do Instituto Federal do Rio Grande do Norte (IFRN), Campus São Paulo do Potengi, no ano de 20186, além dos municípios verificados na REGIC, discentes matriculados no Campus, declaram residir em Caiçara do Rio do Vento, Ielmo Marinho, Sítio Novo, Serra Caiada, Bom Jesus, Macaíba, Boa Saúde, Monte Alegre e Lagoa Salgada e até de Natal, Parnamirim, Currais Novos e São Fernando (que são casos isolados).

Em 2013, tivemos em São Paulo do Potengi a instalação IFRN, fruto de um projeto de expansão que significa na atualidade a consolidação de 22 Campi no estado, localizados tanto

\footnotetext{
${ }^{6}$ A pesquisa considerou todos os alunos matriculados nessa unidade de ensino no ano de 2018 . No ato da matrícula os alunos informam o seu município de residência, sendo essa informação disponibilizada pela Secretaria Acadêmica para a realização nossa pesquisa.
} 
em Centros de Gestão do território como em centros locais. Esses fixos educacionais estão entre os que mais atraem fluxos de diversos municípios do estado, sendo perceptível a influência do território e da importância das cidades na rede urbana para a escolha da instalação dessa atividade.

A espacialização da expansão dos serviços de educação tanto de níveis médio, técnico e superior com os Campi do IFRN, quanto do ensino superior por intermédio das Universidades Federais, Estaduais e privadas, evidenciam que a instalação dessas instituições de ensino no interior do estado ocorreram, predominantemente, em cidades que apresentam relevância no contexto regional da rede urbana potiguar, reforçando a concentração espacial embora, diferentemente, do ocorrido em períodos anteriores quando se tinha uma centralização e concentração ainda mais acentuada. Portanto, tal como ocorre em outros estados do país, como no caso do Rio de Janeiro, estudado por Brito (2014, p. 12-13),

\begin{abstract}
As cidades que recebem tais instalações são aquelas com maior centralidade. Esses campi não são instalados em qualquer município ou em municípios que predominam ruralidades. Eles já detêm um bom nível de urbanidade e em muitos casos (se não todos), já existem instituições de ensino superior de cunho privado ou filantrópico. A interiorização está ocorrendo nos municípios onde são maiores as transformações locais e/ou regionais como o aumento populacional, os investimentos industriais e de variadas atividades econômicas e quando se amplia o nível de integração com a metrópole e com a dinâmica estadual, nacional e internacional.
\end{abstract}

A presença do IFRN em São Paulo do Potengi não foi considerada na classificação dos níveis de centralidade em 2007, pois esse Campus não existia. Mas, é extremamente relevante para o papel e importância que tal cidade tem na rede urbana nesse período, devido a contemplar não apenas municípios de sua zona de influência,-como também de outras microrregiões do estado.

O ensino superior público era uma oferta educacional ainda mais restrita que a educação básica, encontrada apenas em Natal, Mossoró, Caicó, Currais Novos e Macau, até a década de 1970. Entretanto, no período técnico-científico-informacional a partir de uma política pública cujo o objetivo era universalizar e interiorizar a Educação Profissional, Tecnológica e Superior ${ }^{7}$, ocorre um processo de espacialização mais equitativa no território, com a expansão das IES, tanto das esferas pública estadual e federal quanto privada. Nesse

\footnotetext{
${ }^{7}$ Entre 2003 e 2016, a rede de Institutos e Universidade Federais, passaram por um plano de expansão da Educação Superior, Profissional e Tecnológica, que expandiu, ampliou e interiorizou essas unidades de ensino.
} 
sentido, compartilha-se do entendimento de Amorim (2010, p. 183) de que "a modernização histórica e atual do território brasileiro, através de sua densidade técnico-científicoinformacional [...] acaba por influenciar a escolha dos investimentos públicos e privados na alocação dos recursos em educação superior.”.

Além do IFRN que passou a ofertar a Licenciatura em Matemática, em 2019, no ano de 2001, a Universidade Vale do Acaraú (UVA) iniciou suas atividades no território Potengi ${ }^{8}$. As unidades foram instaladas nas cidades de São Paulo do Potengi, Senador Elói de Souza, Bom Jesus e Riachuelo. Contudo, segundo entrevista feita com o fundador e a coordenadora do polo de São Paulo do Potengi, em 2018 funcionavam no território apenas 2 (dois) polos, localizados em São Paulo do Potengi e Riachuelo, assim, reforçando a centralidade exercida principalmente pelo município de São Paulo do Potengi, que concentra uma maior quantidade de alunos dessa instituição. Em São Paulo do Potengi, o curso ofertado pela UVA é Pedagogia e contava com um total em 2018 de 77 alunos, sendo esses residentes nos municípios de Barcelona, Ruy Barbosa, Lagoa de Velhos, São Pedro, Riachuelo, Santa Maria, Senador Elói de Sousa e São Paulo do Potengi (Mapa $1^{9}$ ).

No caso das escolas privadas da cidade, também verificamos que há uma maior área de influência. As escolas funcionam em São Paulo do Potengi desde a década de 1960 e, em 2018, além de contar com alunos provenientes dos municípios verificados no estudo da REGIC de 2008 (Barcelona, Lagoa de Velhos, Santa Maria, Riachuelo, Ruy Barbosa, São Pedro, São Tomé e Senador Elói de Souza), ainda foram identificados alunos residentes nos municípios de Caiçara do Rio do Vento, Bom Jesus e Serra Caiada (Mapa 1). Quanto as escolas públicas que funcionam desde 1935, observamos que há uma correspondência com a área de influência da REGIC de 2008, dado que, em 2019, os municípios de residência dos alunos dessas instituições permanecem os mesmos da área de influência de 2008.

\footnotetext{
${ }^{8}$ Delimitação espacial adotada pelo Ministério do Desenvolvimento Agrário - MDA e pela Secretaria de Desenvolvimento Territorial - SDT a partir da similaridades ambientais, econômicas, culturais, políticas e institucionais. O território do Potengi é formado por onze municípios (Barcelona, Bom Jesus, Ielmo Marinho, Lagoa de Velhos, Riachuelo, Ruy Barbosa, Santa Maria, São Tomé, São Paulo do Potengi, São Pedro e Senador Elói de Souza).

${ }^{9}$ As REGICs, assim como os resultados da pesquisa nos permitiram a produção de mapas de fluxos de todas as variáveis analisadas. Contudo, optamos por representar cartograficamente nesse texto aqueles que devido um maior número de interações territoriais, não apenas contemplam a trama de relações evidenciada nas demais análises, como evidenciam a ampliação da área de influência de São Paulo do Potengi.
} 
Mapa 1: Municípios de residência dos alunos das escolas privadas e UVA de São Paulo do Potengi, em 2019.

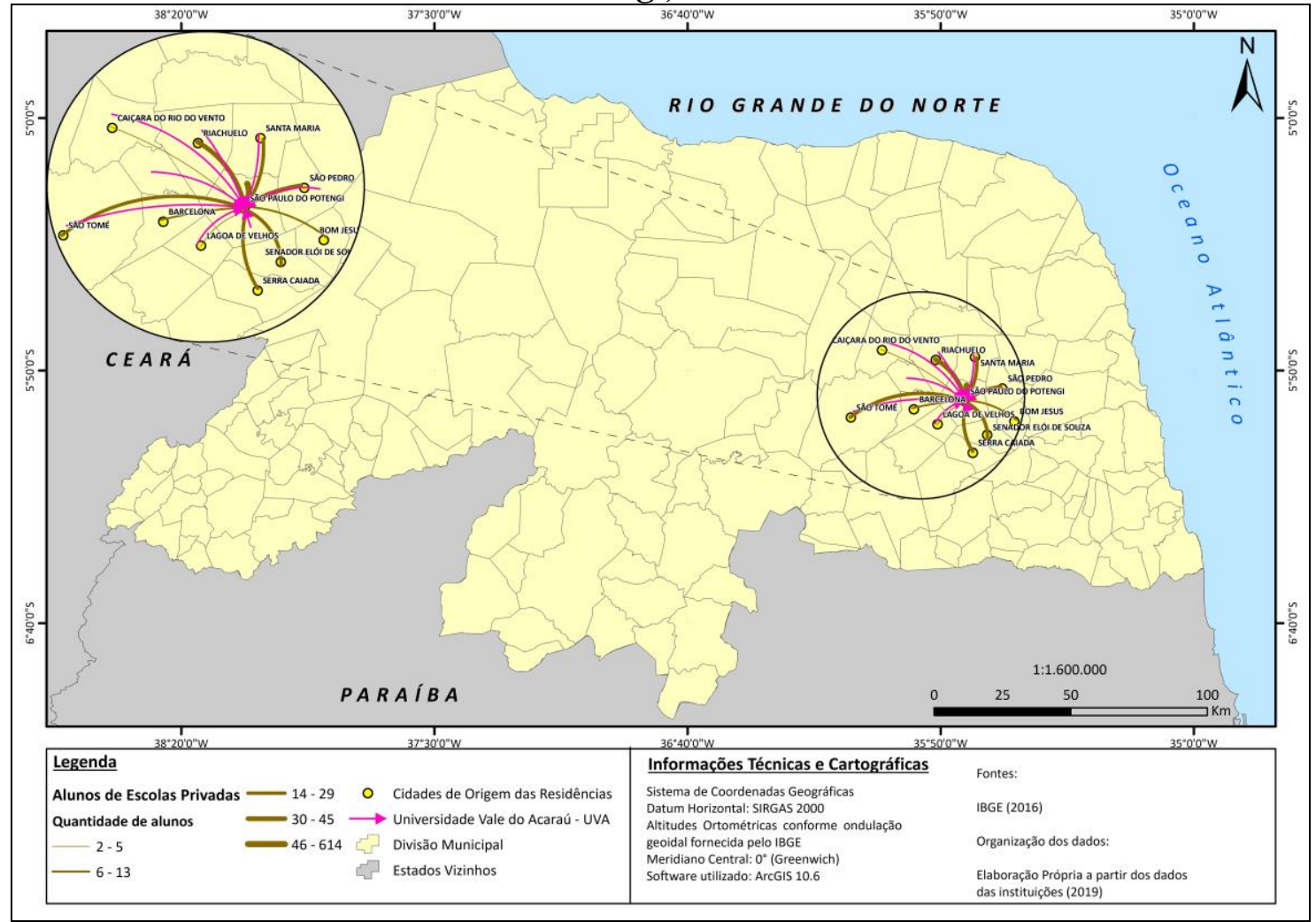

Fonte: Elaboração própria a partir dos dados disponibilizados pelas instituições, 2019.

Na saúde também constatamos a centralidade de São Paulo do Potengi. De acordo com o Plano de Desenvolvimento Rural do Potengi, os equipamentos da rede hospitalar e ambulatorial da região do Potengi "são insuficientes e espacialmente concentrados na sede do território - São Paulo do Potengi” (BRASIL, 2010, p. 42). Segundo o Cadastro Nacional de Estabelecimentos de Saúde (CNES), as unidades públicas apresentam uma boa espacialização para os serviços de atenção básica, existindo 99 (noventa e nove) unidades no total dos municípios do Potengi. No entanto, quanto aos serviços de saúde mais especializados, notamos que há uma maior concentração e área de influência a partir de São Paulo do Potengi.

A partir das pesquisas realizadas em algumas unidades de saúde de São Paulo do Potengi como: o Hospital Regional, Secretaria de Saúde de São Paulo do Potengi, Policlínica do Centro, Policlínica do Novo Juremal, Centro de Especialidade Odontológica (CEO), Centro de Reabilitação Infantil e Adulto (CRIA) e Serviço de Atenção Especial (SAE), foram identificados que além dos municípios mencionados na REGIC, o município ainda recebe população de: Bento Fernandes, Bom Jesus, Serra Caiada, Ielmo Marinho, São 
José do Campestre, Tangará e Boa Saúde (Mapa 2). De acordo com a REGIC de 2008, os fluxos para o serviço de saúde eram de Barcelona, Caiçara do Rio do Vento, Lagoa de Velhos, Santa Maria, Riachuelo, Ruy Barbosa, São Pedro, São Tomé e Senador Elói de Souza.

Mapa 2: Municípios de residência dos pacientes que buscam atendimento nos serviços de saúde pública de São Paulo do Potengi, em 2019.



Fonte: Elaboração própria a partir dos dados disponibilizados pelas instituições, 2019.

Na saúde privada também podemos constatar uma maior densidade em São Paulo do Potengi e ampliação de sua área de influência. Em São Paulo do Potengi existem 5 (cinco) clínicas privadas. E entre os outros municípios não há registro. Considerando a regionalização do Plano Territorial de Desenvolvimento Rural Sustentável do Potengi (PTDRS) que contempla no território do Potengi o município de Bom Jesus, temos o cadastro de 1 (uma) clínica no referido município (CNES/SUS, 2018).

Conforme já mencionado, os fluxos para o serviço de saúde de acordo com a REGIC de 2008, eram de Barcelona, Caiçara do Rio do Vento, Lagoa de Velhos, Santa Maria, Riachuelo, Ruy Barbosa, São Pedro, São Tomé e Senador Elói de Souza, e na pesquisa realizada, em 2018, com três clínicas de saúde privada de São Paulo do Potengi foi 
identificado que são recebidos além de pacientes desses municípios, também aqueles que residem em Campo Redondo, Serra Caiada, Santa Cruz, São José do Campestre, Ielmo Marinho, Bom Jesus e Boa Saúde.

Portanto, podemos constatar que os serviços de educação e saúde já nos dão um indício da expansão da área de influência de São Paulo do Potengi. Situação ratificada com os fluxos que são realizadas por outras atividades em direção a esse centro urbano.

Nesse sentido, destacamos que a própria difusão do meio técnico-científicoinformacional traz novos conteúdos a quase todos os interstícios da vida social. Dentre esses, temos a disseminação de uma série de fixos geográficos destinados à expansão das finanças e à prestação dos serviços bancários. De acordo com Silveira (2015, p. 258),

\footnotetext{
Quanto mais rapidamente se difundem as variáveis do período na rede urbana, através de atividades técnico-científicas, grandes bancos e instituições financeiras, comportando a mais recente vaga de modernização territorial, mais transformações nas articulações verticais entre agentes e atividades se verificam.
}

As novas demandas que são exigidas dos lugares demandam uma adequação do território para permitir que os fluxos financeiros cheguem a todos os pontos. Refletindo sobre essa questão, Santos (1989, p. 79) nos diz que, em meio, a "novas condições trazidas pelo uso da ciência e da técnica na transformação do território, há uma maior expressão do assalariado em formas diversas [...], uma necessidade maior de capital adiantado, o que vai explicar a enorme expansão do sistema bancário.". Assim, teremos, como evidencia Santos (2005, p. 56), ao tratar da nova urbanização, "a presença de ramificações do sistema bancário, até mesmo em núcleos menores", pois o capital financeiro tende a não deixar de lado nenhuma parcela do território.

No Rio Grande do Norte e, ainda no caso de São Paulo do Potengi, a topologia que esses serviços passam a apresentar, indo das agências à "hipercapilaridade das finanças no território" (CONTEL, 2011, p. 249), ou seja, das formas tradicionais às modernas, influenciam a estrutura apresentada pela rede urbana no período atual e as centralidades e área de influência das cidades.

Em São Paulo do Potengi, temos duas agências bancárias, uma do Banco do Brasil e outra do Bradesco. A do Bradesco foi inaugurada em 2011, já a Banco do Brasil, não foi informado exatamente o ano de instalação, mais segundo entrevista realizada com a gerência banco são um pouco mais de 25 anos de atuação na cidade, portanto, entrando em operação a partir da década de 1990. 
Em relação aos correspondentes bancários, que segundo dados do Banco Central do Brasil de 2010, são 11 em São Paulo do Potengi, o impacto sobre a estrutura da rede urbana também se verifica. Conforme elucida Contel (2011), sendo mais flexíveis quanto à sua localização potencial, os correspondentes rapidamente se difundem, capilarizando quase todo o território, principalmente nas suas "áreas opacas". Como requerem um baixo investimento em sistemas técnicos para funcionar, precisando apenas de um funcionário que é treinado pelo próprio banco, energia elétrica, um computador ligado ao banco contratante, telefone fixo ou móvel e são abrigados em um estabelecimento comercial já existente, tais objetos geográficos se expandem nas cidades do estado com mais facilidade (CONTEL, 2011).

Os correspondentes atendem às necessidades básicas requeridas por grande parte da população do interior do estado, sobretudo das cidades menores e não tão dinâmicas, em relação às atividades bancárias, permitindo a expansão da acessibilidade da população a determinados serviços financeiros, sem que seja necessário se recorrer a uma agência que se encontre em outro centro urbano. Estão entre os principais serviços realizados pelos correspondentes: pagamentos simples, depósitos, saques de baixas quantias de dinheiro e recebimento de benefícios sociais. Assim, esse fixo geográfico-financeiro se tornou, no período atual, um dos mais usados pela população do estado, porque está mais próximo e acessível que os tradicionais e não apresenta as dificuldades de operacionalização que os Postos de Atendimento Bancário Eletrônico (PAE's) podem significar para algumas pessoas.

Porém, em São Paulo do Potengi, não apenas as agências, como também os correspondentes instalados em lotéricas, Correios, Pagfácil, farmácias e um dos supermercados evidenciam a centralidade regional desse centro urbano quanto as atividades financeiras e a expansão de sua área de influência nos últimos dez anos, quando esses fixos financeiros se capilarizam no seu território. Para além dos clientes que coincidem com os deslocamentos verificados para São Paulo do Potengi na última REGIC, a cidade ainda recebe fluxos para o uso desse serviço de Boa Saúde, Bom Jesus, Caiçara do Rio do Vento, Serra Caiada e alguns casos mais pontuais de Macaíba e Natal (Mapa 3), evidentemente, que no caso desses dois últimos por alguma outra particularidade que não é a influência regional sobre esses municípios que dispõem de uma maior densidade desses objetos. 
Mapa 3: Municípios de residência dos clientes que buscam atendimento nos serviços de bancários e financeiros de São Paulo do Potengi, em 2019.

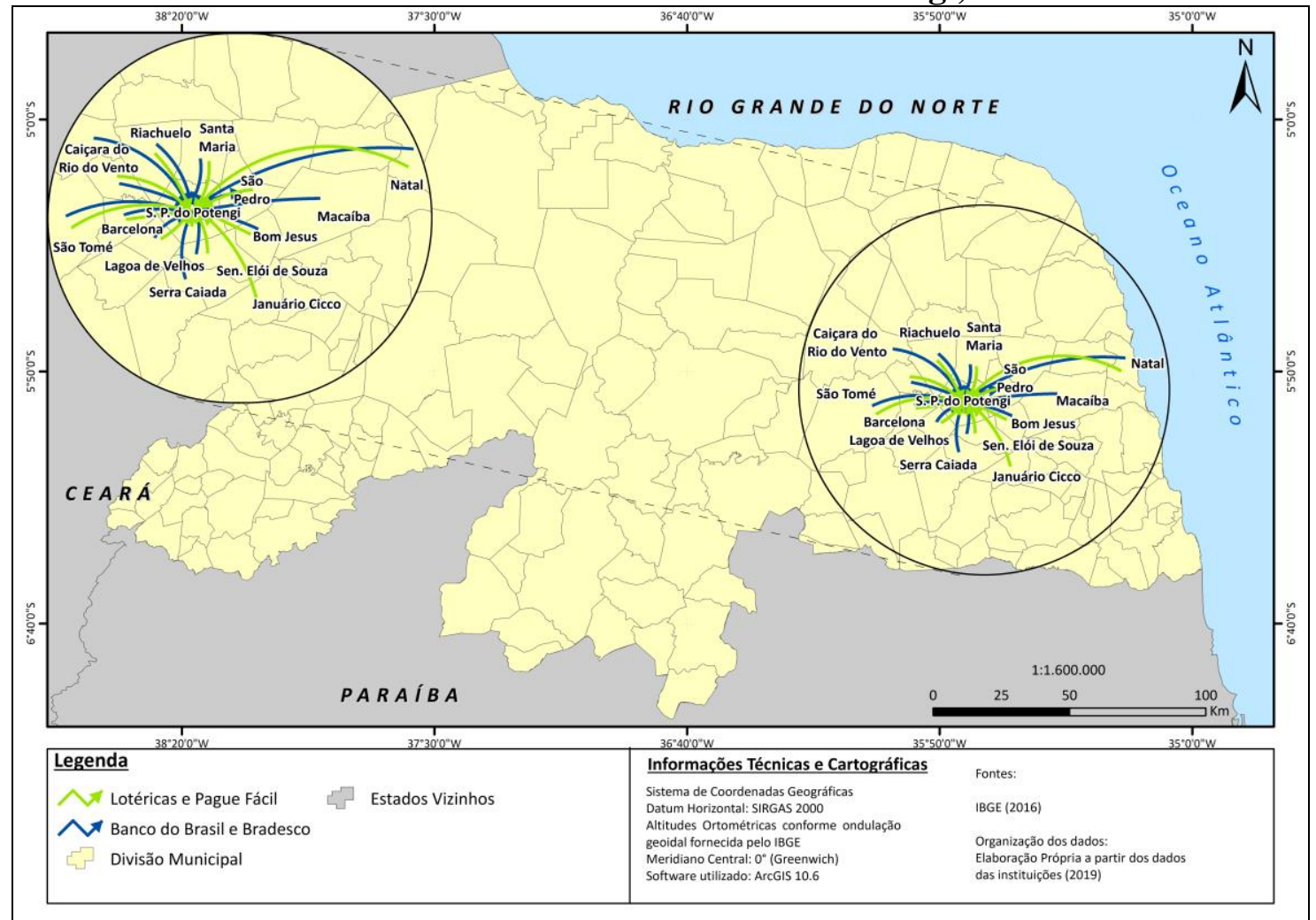

Fonte: Elaboração própria a partir dos dados disponibilizados pelas instituições, 2019.

Assim, destacamos a importância que a presença dessas agências e a hipercapilaridade das atividades bancárias e finanças por intermédio dos correspondentes tem nesse território. Esses bancos são uma grande fonte de recebimento de contas de serviços públicos, pagamentos de salários da esfera pública e também privada e são instituições que pagam uma quantidade significativa de pensões, aposentadorias e benefícios sociais. Destarte, assim como ocorre em outros lugares, a maior dinamicidade econômica no território do estado solicita a expansão de atividades bancárias, as quais, por sua vez, também criam uma maior dinâmica econômica, dado que, como nos lembra Silveira (2007, p. 161), "um tecido financeiro onipresente exerce influência sobre as formas e normas de consumo das classes médias e dos pobres".

Além dos serviços já elencados, um outro serviço que evidencia as áreas de influência dos centros urbanos é o judiciário. É preciso destacar que a gestão federal é um dos critérios utilizados pela última REGIC, para classificar os centros de gestão do território da rede urbana nacional e que uma das variáveis, contempla, portanto, a hierarquia do setor judiciário federal. Analisando os fluxos para o cartório de São Paulo do Potengi da jurisdição 
eleitoral que compreendem a Justiça Eleitoral da União faz-se notório que se mantem a centralidade para poucos municípios, os quais estão na área de influência já identificada pelo IBGE, sendo Riachuelo, Santa Maria e São Pedro. Além do Cartório Eleitoral, o Fórum Municipal também demonstra situação semelhante atendendo apenas os municípios de Riachuelo e São Tomé. Apenas a $1^{\circ}$ Delegacia Regional, que se localiza em São Paulo do Potengi e, foi inaugurada na década de 80, é que evidencia uma maior área de influência, já que para além dos municípios da REGIC 2008, atende Caiçara do Rio dos Ventos, Lajes, Pedra Preta, Bom Jesus, Vera Cruz, Monte Alegre e Nísia Floresta. Contudo, alguns desse municípios têm suas delegacias municipais como Nísia Floresta e Monte Alegre.

\section{COMÉRCIO VAREJISTA MODERNO}

São Paulo do Potengi ainda apresenta uma feira importante, estando entre as maiores feiras do Agreste potiguar, segundo a maioria dos feirantes é a maior da região. Como esclarece Corrêa (2005, p. 50), “os mercados periódicos são definidos como aqueles núcleos de povoamento, pequenos, via de regra, que periodicamente se transformam em localidades centrais", porque "nos dias de mercado, o pequeno núcleo transforma-se em um centro de mercado". Assim, associada as demais atividades, a feira constitui mais um dos elementos relevantes para a centralidade exercida por essa cidade no Rio Grande do Norte, assim como também revela a expansão da área de influência desse centro urbano, ponderando que segundo os feirantes, a feira ainda atrai fluxos de Serra Caiada, Tangará e São José do Campestre.

Quanto à distribuição espacial do comércio varejista, entendemos que é um dos elementos essenciais para compreendermos a configuração de uma rede urbana, considerando que seja na escala intra ou interurbana "a análise do comércio permite uma melhor compreensão do espaço urbano, na medida em que comércio e cidade são elementos indissociáveis" (PINTAUDI, 2005, p. 144). A localização dos fixos do setor de varejo em seus diversos segmentos cria fluxos significativos de interações entre os territórios. Assim, os centros urbanos que apresentam uma maior densidade e variedade de comércio varejista exercem maior centralidade no contexto da rede urbana, enquanto naqueles onde o setor é mais raro e o atendimento da demanda se restringe às necessidades básicas predominam centros cuja área de influência é local. 
A própria expansão dos objetos geográficos bancários, educacionais, de saúde e judiciários, associadas a presença das redes técnicas de telecomunicações e transportes, propiciam e demandam nas cidades uma dinâmica econômica que não se tinha antes desse período. Essa dinâmica pode ser constatada pela expansão do comércio varejista de diversos ramos. A expansão do comércio varejista se dá, no período atual, pela presença de vários fatores que podem ocorrer, juntos ou não, dos quais destacamos: a ampliação do crédito e a geração de renda promovida pelos salários dos servidores públicos de todas esferas, pelo grande volume de aposentadorias e beneficiários de programas sociais e ainda pela presença de etapas de alguns circuitos produtivos ${ }^{10}$.

O comércio varejista, segundo Costa (1977), era a modalidade de comércio que predominava no estado até a década de 1970, contudo apresentava um número reduzido nos municípios pequenos, muitos sendo classificados como "bodegas". A partir dos anos 1990, o comércio varejista do Rio Grande do Norte apresenta um contexto completamente diferente, uma vez que se verifica uma ampla difusão do setor, embora apresentando conformações distintas nos subespaços do território potiguar. Conforme observamos, esse período é marcado pela expansão das grandes redes de comércio varejista na capital potiguar. Todavia também há o crescimento e a modernização dessa atividade em outros centros urbanos do estado. Mas, com o surgimento em diversos setores de atividades comerciais menos modernas que as encontradas no circuito superior "puro", apresentando "menor capital, porém capazes de absorver a porcentagem da população marginalizada" (SANTOS, 1994, p. 94).

Em todos os centros urbanos do estado, dos centros de gestão do mais alto nível hierárquico aos centros locais, há no período atual uma variada classe média e pobre, que devido ao crédito e à tecnificação da circulação, tem ampliado e diversificado o consumo (SILVEIRA, 2009). Entretanto, trata-se de uma das diferentes formas de consumir, uma vez que, como nos alerta Arroyo (2008), a "segmentação do mercado autoriza a convivência de uma ampla variedade de formas de realização econômica". Assim, além da existência dos circuitos superior e inferior, temos o circuito superior marginal, o qual "trabalha segundo parâmetros modernos, o que o aproxima do circuito superior, mas é, em grande parte, resposta às necessidades de consumo localmente induzidas, o que o aproxima do circuito inferior"

${ }^{10}$ Até os anos 1960/1970, predominavam entre as principais atividades econômicas do estado, a pecuária, o algodão, a atividade salineira e o extrativismo mineral e vegetal. No entanto, após a crise dessas atividades, surgem novas atividades, as quais são carregadas de técnica e ciência e promovem uma nova dinâmica econômica nos territórios em que se instalam, como por exemplo: petróleo, fruticultura irrigada, indústria têxtil e de alimentos. 


\section{SOCIEDADE E}

TERRITÓRIO
TAVARES, Edseisy Silva Barbalho

GOMES, Dina

PORFÍRIO, Escarlaty

(SANTOS, 1994, p. 96). Nesse circuito da economia urbana moderna no estado, encontramse, por exemplo, as redes de diversos segmentos formados principalmente pelo associativismo de grupos locais e regionais. Esse instalado nas faixas de mercado e áreas geográficas onde o circuito superior "não querem ou não podem operar" (SANTOS, 1994, p. 97).

É diante desse processo de expansão e interiorização do comércio varejista e também, em particular, dessas redes no território potiguar, que temos mais uma variável que estabelece novos fluxos e influencia a estrutura da rede urbana no estado.

Quanto a centralidade de São Paulo do Potengi, se refere a mais uma variável que evidencia a ampliação de sua área de influência, contemplando fluxos além dos captados pela última REGIC, principalmente de Boa Saúde, Bom Jesus, Caiçara do Rio do Vento, São Tomé e Serra Caiada (Mapa 4). A expansão e interiorização desse comércio possibilita ao consumidor a opção de uma variedade de produtos e preços competitivos que anteriormente só eram possíveis com o deslocamento aos centros que estão nas posições de maior nível de centralidade da rede urbana estadual.

\section{Mapa 4: Municípios de residência dos clientes que buscam o comércio varejista de São}

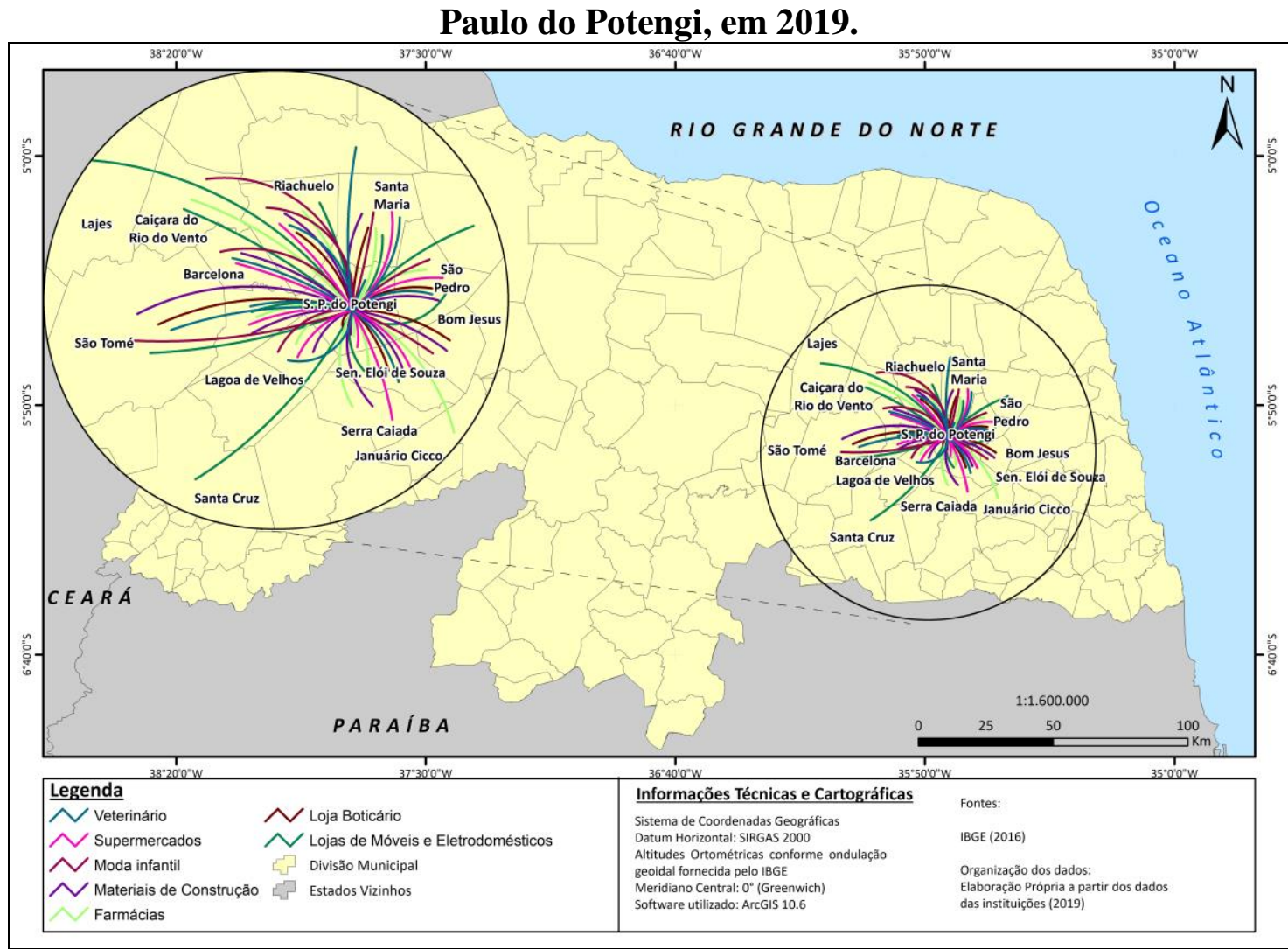

Fonte: Elaboração própria a partir dos dados disponibilizados pelas empresas, 2019. 


\section{CONSIDERAÇÕES FINAIS}

As modificações do papel e das funções das cidades na rede urbana estão atreladas entre outras questões, a expansão da infraestrutura de transporte e telecomunicações, ao aumento da prestação dos serviços privados e públicos em todas as esferas e em função da expansão do comércio varejista de produtos diversos, mas principalmente, nos setores supermercadista, de móveis e eletrodomésticos, construção e farmácias que passaram a se instalar em diversas áreas urbanas do território do estado.

Há, no período atual, uma coabitação dessas redes, que possibilitam às cidades de diferentes níveis hierárquicos mudarem os seus papeis, funções e área de influência na rede urbana do estado a partir da instalação desses novos fixos e dos fluxos que movimentam. Compreender a superposição das redes e como se estabelecem as interações territoriais é fundamental para o entendimento da situação urbana de uma cidade como São Paulo do Potengi, assim como em relação aos centros com os quais interagem, dado que nos evidencia onde se localizam as atividades, quais hierarquias que se configuram para cada tipo de rede e qual é a área de influência atendida por diferentes tipos de atividades.

São Paulo do Potengi a partir do papel e das funções que desempenha é considerada com uma cidade intermediária (regional) (SANTOS, 2008), que tem a função de "proporcionar serviços de nível médio e produtos mais diversificados do que as cidades locais podem vender." (SANTOS, 2008, p. 72). E, a partir das variáveis do período técnicocientífico-informacional, permanece mantendo fluxos realizados para algumas atividades que são os mesmos constatados na REGIC 2008. Porém, revela claramente como a instalação de uma nova lógica de transportes, infraestrutura de telecomunicações e, principalmente novos equipamentos comerciais e de serviços, ampliam a sua área de influência, a qual passou a contemplar Boa Saúde, Bom Jesus, Caiçara do Rio do Vento, Ielmo Marinho e Serra Caiada.

A própria delimitação espacial adotada pelo MDA e pela SDT que considera características ambientais, econômicas, culturais, políticas e institucionais similares, já evidencia um pouco dessa nova realidade, dado que compreende na circunscrição territorial do Potengi 11 (onze) municípios, que são Barcelona, Bom Jesus, Ielmo Marinho, Lagoa de Velhos, Riachuelo, Ruy Barbosa, Santa Maria, São Tomé, São Paulo do Potengi, São Pedro e Senador Elói de Souza.

Dessa forma, as mudanças de usos do território promovida por essas novas situações, além de reduzir a rigidez da hierarquia urbana, devido à coexistência de diversas redes e 
hierarquias, ainda possibilita novas funções a esse centro urbano que já esteve no nível mais elementar da rede urbana do estado.

\section{REFERÊNCIAS}

AMORIM, Cassiano Caon. O uso do território brasileiro e as Instituições de Ensino Superior. 2010, 335 f. Tese (Doutorado em Geografia). Departamento de Geografia da Faculdade de Filosofia, Letras e Ciências Humanas da Universidade de São Paulo, 2010.

ARROYO, Mónica. A economia invisível dos pequenos. Le Monde Diplomatique Brasil. 2008. Disponível em: <http://www.diplomatique.org.br/artigo.php?id=283>. Acesso em: 12 set. 2018.

BESSA, Kelly. Os processos de diferenciação entre os centros e a reestruturação da rede urbana: a dinâmica recente do segmento no Tocantins. In.: XVI Encontro Nacional dos Geógrafos: crise, práxis e autonomia: espaço de resistência e de esperanças. Porto Alegre, 2010 .

BRASIL. 2010. Banco Central do Brasil. Relação de agências e postos bancários (transferência de arquivos). Disponível em: <http://www.bcb.gov.br/?RELAGPAB>. Acesso em: 28 fev. 2019.

Plano de Desenvolvimento Rural do Potengi. 2010. Disponível em:

<http://sit.mda.gov.br/download/ptdrs/ptdrs_qua_territorio123.pdf>. Acesso em: 25 de abril de 2020.

INSTITUTO BRASILEIRO DE GEOGRAFIA E ESTATÍSTICA (IBGE). IBGE. 2005. Pesquisa Nacional por Amostra de Domicílios. Disponível em:

<http://www.sidra.ibge.gov.br/pnad/default.asp>. Acesso em: 27 mar. 2019.

INSTITUTO BRASILEIRO DE GEOGRAFIA E ESTATÍSTICA (IBGE).. Pesquisa

Nacional por Amostra de Domicílios. Suplemento Acesso à Internet e à Televisão e Posse de Telefone Móvel Celular para Uso Pessoal - 2013. Disponível em:

<http://www.sidra.ibge.gov.br/pnad/default.asp>. Acesso em 27 de março de 2019.

INSTITUTO BRASILEIRO DE GEOGRAFIA E ESTATÍSTICA. IBGE.

2008. Regiões de Influência das Cidades 2007. Rio de Janeiro: IBGE, 2008.

BRASIL, Ministério da Saúde. Cadastro Nacional de Estabelecimentos de Saúde. 2018. Departamento de Informática do SUS. Disponível em: <http://cnes.datasus.gov.br>. Acesso em: 20 nov. 2018. 
BRITO, Leonardo Chagas de. A importância dos estudos sobre interiorização da Universidade e reestruturação territorial. Revista brasileira de geografia econômica, ano II, n. 4, p. 1-17, 2014.

CASTELLS, Manuel. A sociedade em rede: a era da informação: economia, sociedade e cultura. Trad. Roneide Venâncio Majer. São Paulo: Paz e Terra, 1999.

CONTEL, Fábio Betioli. Território e finanças: técnicas, normas e topologias bancárias no Brasil. São Paulo: Annablume, 2011.

CORRÊA, Roberto Lobato. Trajetórias geográficas. 3 ed. Rio de Janeiro: Bertrand Brasil, 2005.

COSTA, Eunice Correia da. O fato urbano no Rio Grande do Norte: características das bases da vida de relações. 1977. 139 f. Dissertação (Mestrado em Geografia). Departamento de Geografia da Faculdade de Filosofia, Letras e Ciências Humanas da Universidade de São Paulo. São Paulo, 1977.

PINTAUDI, Silvana Maria. A cidade e as formas do comércio. In: CARLOS, Ana Fani Alessandri (Org.). Novos caminhos da geografia. 5. ed. São Paulo: Contexto, 2005.

SANTOS, Milton. Meio técnico científico e urbanização: tendências e perspectivas. Revista Resgate. Comunicação apresentada no Seminário Brasil século XXI, "Seção Campo e cidade na virada do século, UNICAMP, 04 abr. 1989. p. 76-86.

Técnica, Espaço e Tempo: globalização e meio técnico-científico-informacional. 5. ed. São Paulo: Editora da Universidade de São Paulo, 1994.

A urbanização brasileira. 5. ed. São Paulo: Editora da Universidade de São Paulo, 2005.

Da totalidade do lugar. São Paulo: Editora da Universidade de São Paulo, 2008.

A Natureza do espaço: técnica e tempo, razão e emoção. 4. ed. São Paulo: Editora da Universidade de São Paulo, 2012.

SANTOS, Milton; SILVEIRA, Maria Laura. O Brasil: território e sociedade no início do século XXI. 5. ed. Rio de Janeiro: Record, 2003.

SILVEIRA, Maria Laura. Metrópolisbrasileñas: um análisis de los circuitos de la economia urbana. Revista eure. Santiago do Chile. vol. XXXIII, n. 100, 2007, p. 149-164. 2007.

Finanças, consumo e circuitos da economia urbana na cidade de São Paulo.

Caderno CRH, Salvador, v. 22, n. 55, p. 65-76, jan./abr. 2009.

Modernização contemporânea e nova constituição dos circuitos da economia urbana. Geousp - Espaço e Tempo. São Paulo, v. 19, n. 2, p. 246-262, ago. 2015. 
SPÓSITO, Maria Encarnação Beltrão. Novas formas comerciais e redefinição da centralidade urbana. In.: SPÓSITO, Maria Encarnação Beltrão (Org.). Textos e contextos para a leitura geográfica de uma cidade média. Presidente Prudente: [s.n.], 2001.

Novas redes urbanas: cidades médias e pequenas no processo de

globalização. Geografia, Rio Claro, v. 35, n.1, p. 51-62. Jan./abr. 2010.

TELECO. Inteligência em Telecomunicações. Relação de Municípios cobertos com 4G por Região SMP (Ago/19).Disponível:<

https://www.teleco.com.br/4g_cobertura.asp?rel_mun=1\#Rel_mun_4g>. Acesso em: $21 \mathrm{dez}$. 2018.

Recebido em Setembro de 2019

Aceito em Março de 2020

Publicado em Julho de 2020 